\title{
Intentional Toxic Ingestion of Sodium Fluoride: A Case Report
}

\author{
Rachel E. Bridwell ${ }^{1}$, Brandon M. Carius ${ }^{1}$, Eric B. Tomich ${ }^{2}$, Joseph K. Maddry ${ }^{1}$ \\ 1. Emergency Medicine, Brooke Army Medical Center, Fort Sam Houston, USA 2. Emergency Services, Highline Medical \\ Center, Burien, USA
}

Corresponding author: Rachel E. Bridwell, r.e.bridwell@gmail.com

\begin{abstract}
Sodium fluoride is an accessible and frequently used compound that if ingested can cause ventricular dysrhythmias, hemorrhage, and death. We present a case report of a 21 -year-old female who presented following an intentional ingestion of a lethal dose of sodium fluoride, developing massive hemorrhage and cardiac arrest.
\end{abstract}

Categories: Emergency Medicine

Keywords: sodium fluoride, toxic ingestion, gastrointestinal hemorrhage, dysrhythmia

\section{Introduction}

Sodium fluoride $(\mathrm{NaF})$ is a colorless, odorless powder readily available online at $98 \%$ pure reagent for use as an insecticide, homemade toothpaste, and wheel cleaner, with an estimated lethal dose of 70-140 mg/kg, or 5-10 g [1-2]. The combination of electrolyte derangements and mucosal corrosion with NaF toxic ingestions (TIs) produces life-threatening complications, including cardiac dysrhythmia, coagulopathy, and gastrointestinal hemorrhage [3-5]. Here, we describe a fatal case of NaF TI.

\section{Case Presentation}

A 21-year-old female presented to the ED via emergency medical services (EMS) transport. Her father found the patient unresponsive in a local park, after reportedly consuming a $226 \mathrm{~g}$ bottle of $99.9 \% \mathrm{NaF}$ powder in a suicide attempt. The EMS found the patient in the field with a depressed mental status and intermittent vomiting, and intubated her using $10 \mathrm{mg}$ of etomidate, $100 \mathrm{mg}$ of succinylcholine, $50 \mathrm{mg}$ of rocuronium, and $4 \mathrm{mg}$ of midazolam.

Received 05/28/2019

Review began 05/31/2019 Review ended 06/20/2019 Published 06/28/2019

๑) Copyright 2019 Bridwell et al. This is an open access article distributed under the terms of the Creative Commons Attribution License CC-BY 3.0., which permits unrestricted use, distribution, and reproduction in any medium, provided the original author and source are credited.
Upon presentation to the ED, vital signs were a blood pressure of $99 / 63 \mathrm{mmHg}$, heart rate of 115 beats per minute (bpm), and pulse oximetry of $100 \%$, with a Glasgow Coma Scale score of 3T. Physical examination was limited due to intubation and sedation, though remaining examination was generally unremarkable. Initial electrocardiogram (ECG) showed sinus tachycardia with a rate of $125 \mathrm{bpm}$ and normal QRS and QTc intervals. Initial laboratory findings showed prominent hypocalcemia of $7.3 \mathrm{mg} / \mathrm{dL}$ with ionized calcium of $0.88 \mathrm{mmol} / \mathrm{L}$, and hypomagnesemia of $1.5 \mathrm{mg} / \mathrm{dL}$. Initial hemoglobin (Hgb) and hematocrit (Hct) were 13.6 $\mathrm{g} / \mathrm{dL}$ and $40 \%$, with a glucose of $140 \mathrm{mg} / \mathrm{dL}$. Additional urine drug screening was negative. An orogastric tube (OGT) was placed with gastric lavage, and $4 \mathrm{~g}$ of magnesium and a $1 \mathrm{~L}$ bolus of normal saline were given intravenously. Fentanyl and midazolam were used to maintain sedation.

Toxicology consultation recommended large supplemental calcium and magnesium and nephrology consultation. Central vascular access with a Quinton catheter was obtained via the right internal jugular vein. A widening QRS on telemetry prompted additional large doses of calcium and magnesium were administered. Two hours after arrival, the patient lost pulses with ventricular fibrillation. Cardiopulmonary resuscitation (CPR) was initiated, with administration of sodium bicarbonate, magnesium, and calcium. During compressions, the patient maintained good oxygen saturation and demonstrated purposeful motor function. However, repeat rhythm checks revealed asystole or pulseless electrical activity despite multiple doses of epinephrine, prompting a continuous epinephrine infusion.

Large volumes of blood were then noted in the OGT and endotracheal tube. Repeat laboratory findings revealed acute anemia, with $\mathrm{Hgb}$ and Hct now $7.1 \mathrm{~g} / \mathrm{dL}$ and $21 \%$, respectively. Massive transfusion protocol was initiated with four units of packed RBCs immediately given. Despite these interventions, the patient did not achieve return of spontaneous circulation, and resuscitative efforts were terminated 90 min later.

\section{Discussion}

$\mathrm{NaF}$ ingestion rapidly generates life-threatening physiologic derangements, including hyperkalemia, hypomagnesemia, and hypocalcemia. While formation of CaF2 was the proposed mechanism of hypocalcemia, in vitro models showed the main species fluorapatite, Ca5(PO4)3F, consumes five Ca2+ per F- 
, occurring at a rate that outpaces mobilization of bone $[3,6]$. In addition to electrolyte derangements, strong binding affinity to a variety of metalloproteases generates widespread metabolic dysfunction [3]. Aerobic metabolism disruption and resulting metabolic lactic acidosis increase cell membrane permeability, making hyperkalemia more difficult to correct [2-4, 7-9].

Ventricular dysrhythmias occur within 90 min in large ingestions [5, 10-11]. A deadly synthesis of hypocalcemia and hyperkalemia was originally considered the culprit of dysrhythmias [12-14]. However, electrolyte correction does not necessarily reverse cardiotoxicity as multiple cases demonstrate normokalemic ventricular dysrhythmia or normocalcemia with fatal hyperkalemia [3, 8-9, 14-15]. Intrinsic F- toxicity and negative inotropy may instead account for cardiac dysrhythmia $[8,16]$. These complex toxicology patients have multiple mechanisms of derangement, requiring frequent electrolyte measurements and ECGs [7].

Hemorrhage is driven in part by prothrombin time prolongation and hypocalcemia coagulopathy. Vascular erosion from F- risks severe hemorrhagic gastritis, necessitating treatment with calcium chloride lavage as part of emergent stabilization [3]. Without control, hemorrhagic emesis can complicate ventilatory and circulatory status [10].

Rapid stabilization is paramount in $\mathrm{NaF}$ TIs with precipitous clinical decline. Along with $\mathrm{CPR}$ requiring up to 40 defibrillations, early endotracheal intubation facilitates nasogastric tube placement for gastric lavage, hemorrhagic aspirate protection, and enteral calcium administration [3-5, 7, 17]. Lavage goals should target $1 \mathrm{~g}$ of calcium using $10 \%$ calcium gluconate per gram of calculated fluoride, with frequent cation checks [3]. Case reports demonstrated survival with massive enteral and parenteral calcium administration during resuscitation [18-19]. Other more invasive treatments include endoscopy within $96 \mathrm{~h}$ and early hemodialysis for management of refractory hyperkalemia $[7,15]$.

\section{Conclusions}

In this case, intentional $\mathrm{NaF}$ ingestion resulted in rapid clinical deterioration and fatal cardiac dysrhythmia. Early administration of calcium and magnesium, treatment of dysrhythmias, and emergent dialysis for correction of electrolyte imbalances may prevent death.

\section{Additional Information}

\section{Disclosures}

Human subjects: Consent was obtained by all participants in this study. Conflicts of interest: In compliance with the ICMJE uniform disclosure form, all authors declare the following: Payment/services info: All authors have declared that no financial support was received from any organization for the submitted work. Financial relationships: All authors have declared that they have no financial relationships at present or within the previous three years with any organizations that might have an interest in the submitted work. Other relationships: All authors have declared that there are no other relationships or activities that could appear to have influenced the submitted work.

\section{References}

1. Service AHF: AHFS Drug Information. McEvoy GK (ed): American Society of Health-System Pharmacists, Bethesda, MD; 2006. http://www.ahfsdruginformation.com/

2. Abukurah AR, Moser AM, Baird CL, Randall RE, Setter JG, Blanke RV: Acute sodium fluoride poisoning . J Am Med Assoc. 1972, 222:816. 10.1001/jama.1972.03210070046014

3. Chan BS, Duggin GG: Survival after a massive hydrofluoric acid ingestion . J Toxicol Clin Toxicol. 1997, 35:307-309.

4. Kao WF, Dart RC, Kuffner E, Bogdan G: Ingestion of low-concentration hydrofluoric acid: an insidious and potentially fatal poisoning. Ann Emerg Med. 1999, 34:35-41.

5. Su YJ, Lu LH, Choi WM, Chang KS: Survival after a massive hydrofluoric acid ingestion with ECG changes . Am J Emerg Med. 2001, 19:458-460. 10.1053/AJEM.2001.24503

6. Heard K, Delgado J: Oral decontamination with calcium or magnesium salts does not improve survival following hydrofluoric acid ingestion. J Toxicol Clin Toxicol. 2003, 41:789-792.

7. Whiteley PM, Aks SE: Case files of the Toxikon Consortium in Chicago: survival after intentional ingestion of hydrofluoric acid. J Med Toxicol. 2010, 6:349-354. 10.1007/s13181-010-0088-4

8. Vohra R, Velez LI, Rivera W, Benitez FL, Delaney KA: Recurrent life-threatening ventricular dysrhythmias associated with acute hydrofluoric acid ingestion: observations in one case and implications for mechanism of toxicity. Clin Toxicol. 2008, 46:79-84. 10.1080/15563650701639097

9. Kavakli AS, Kavrut Ozturk N: Recurrent ventricular fibrillation associated with acute ingestion of hydrofluoric acid. J Clin Anesth. 2018, 46:8-9. 10.1016/J.JCLINANE.2018.01.009

10. Menchel SM, Dunn WA: Hydrofluoric acid poisoning. Am J Forensic Med Pathol. 1984, 5:245-248.

11. Manoguerra AS, Neuman TS: Fatal poisoning from acute hydrofluoric acid ingestion. Am J Emerg Med. 1986, 4:362-363.

12. McIvor ME, Cummings CE, Mower MM, et al.: Sudden cardiac death from acute fluoride intoxication: the role of potassium. Ann Emerg Med. 1987, 16:777-781

13. Cummings CC, McIvor ME: Fluoride-induced hyperkalemia: the role of Ca2+-dependent $\mathrm{K}+$ channels . Am J 


\section{Cureus}

Emerg Med. 1988, 6:1-3.

14. Heard K, Hill RE, Cairns CB, Dart RC: Calcium neutralizes fluoride bioavailability in a lethal model of fluoride poisoning. J Toxicol Clin Toxicol. 2001, 39:349-353.

15. Yolken R, Konecny P, McCarthy P: Acute fluoride poisoning. Pediatrics. 1976, 58:90-93.

16. Strubelt O, Iven H, Younes M: The pathophysiological profile of the acute cardiovascular toxicity of sodium fluoride. Toxicology. 1982, 24:313-323.

17. Maddry JK, Kester A, Heard K: Prolonged hypocalcemia refractory to calcium gluconate after ammonium bifluoride ingestion in a pediatric patient. Am J Emerg Med. 2017, 35:378-381. 10.1016/j.ajem.2016.08.028

18. Greco RJ, Hartford CE, Haith LR, Patton ML: Hydrofluoric acid-induced hypocalcemia. J Trauma. 1988, 28:1593-1596.

19. Stremski ES, Grande GA, Ling LJ: Survival following hydrofluoric acid ingestion. Ann Emerg Med. 1992, 21:1396-1399. 